\title{
Argentine crisis rattles cosmic-ray hunters
}

\section{Carol Marzuola}

Astrophysicists awaiting the Pierre Auger Observatory's high-energy cosmic-ray data are keeping a nervous eye on the political and economic crisis in Argentina, where the Southern Hemisphere arm of the observatory is due to be completed by 2005 .

Two hundred and fifty researchers from 19 countries are involved in the US\$50-million project to build the world's largest cosmicray observatory. It will study cosmic radiation - the flow of charged particles from space that streams through the Earth's atmosphere and, in particular, the rare and mysterious particles of very high energies.

The southern part of the observatory, in Argentina's Mendoza province, is being built first. The northern arm, to be located in the United States, will come later. Argentina had pledged $\$ 15$ million to the project, but since December 2001, when the Argentinian peso was devalued, the country has plunged deeper into economic and political crisis (see Nature 415, 104; 2002) and is unlikely to fulfil all of its obligations.

High-energy cosmic rays intrigue physicists because they cannot identify astrophysical objects or events, such as colliding galaxies, that are sufficiently violent to explain the rays' origins. But high-energy particles of $10^{20}$ electron volts or more hit the Earth's atmosphere only rarely — about once per $\mathrm{km}^{2}$ per century.

The Auger observatory will use two sets of detectors to find these cosmic rays. At each site, 1,600 surface detectors - large aboveground water tanks equipped with photomultipliers - will identify secondary cosmic -ray showers produced in the atmosphere by incoming rays. Additionally, 24 special telescopes will detect fluorescence produced by the particles as they pass through the atmosphere.

A prototype array of 30 detectors and two telescopes was completed last year in Argentina and has already produced useful data, says James Cronin of the University of Chicago, a joint leader of the Auger project.

Alberto Etchegoyen, an official at Argentina's atomic-energy commission and the project's southern spokesman, says that the transitional Argentinian government has no clear long-term plans for science or technology, and admits that the project may have to find some of the promised funding from other sources. Project supporters in Argentina and Brazil, for example, are jointly seeking a \$3-million grant from an international development bank fund for Brazil to enable them to participate.

Optimists also point out that the devaluation of the peso will make the dollars and euros of the project's other contributing nations go further in Argentina. Paul

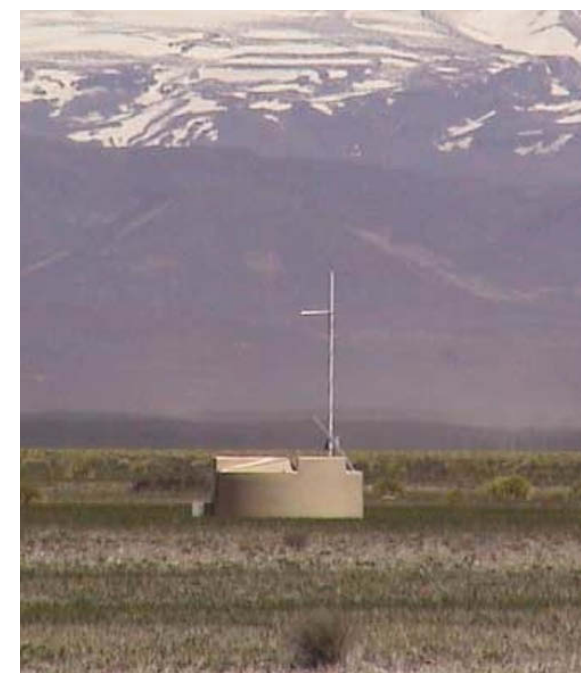

Mantsch, a project manager for Auger at the Fermi National Accelerator Laboratory in Batavia, Illinois, says: "We're really optimistic that when the time comes to make up what's missing, we can do that."

Nonetheless, Auger's participants continue to worry. At the April meeting of the American Physical Society in Albuquerque,

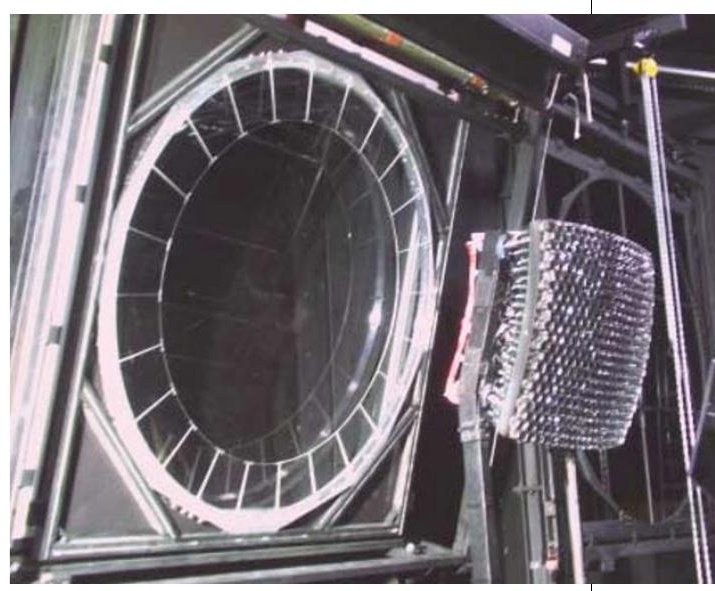

Cosmic detection: a surface detector (left) and telescope camera (above) in place in Mendoza.

New Mexico, physicist Michael Turner of the University of Chicago urged US funding agencies to "ensure timely completion and operation" of the observatory in case there was a problem. "The whole future of this field hinges upon the result of the southern Auger," he said.

www.auger.org

\section{Mummy's silence broken at last}

Rex Dalton, Tucson

The lock on a 2,000-year-old mummy's scientific secrets has been opened by a South African archaeologist - after a three-year wrangle with local tribes and landowners over its custody.

Johan Binneman, archaeology curator at the Albany Museum in Grahamstown, found the mummy in 1999, during an approved expedition at a hunter-gatherer shelter site in the Kouga Mountains in South Africa's Eastern Cape province.

But government officials refused to let Binneman, whose work was publicly funded, present scientific data on the Kouga mummy until last month, when he attended the biennial conference of the Society of Africanist Archaeologists at Tucson, Arizona.

Last September, Maryna Steyn, a physical anthropologist at the University of Pretoria who worked with Binneman, was unable to present a manuscript on the specimen at the fourth World Congress on Mummy Studies in Greenland, pending approval by South African government officials.

The mummy is $145 \mathrm{~cm}$ tall and is thought to be a male of 50-55 years of age, possibly a shaman or a tribal chief. It was found in a near-fetal position - with its feet bound and wrapped in leaves of a poisonous plant (Boophane disticha), a well-known coagulant.

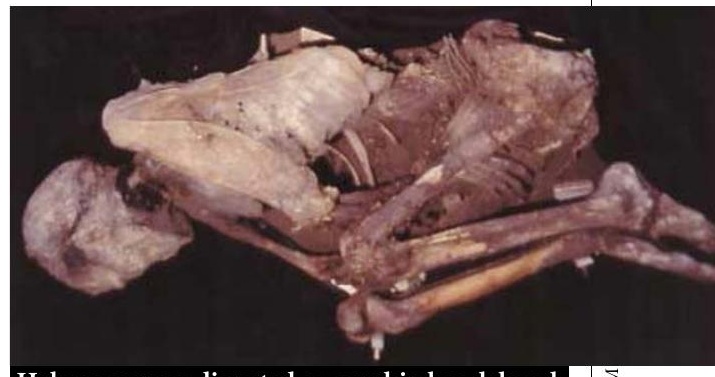

Habeas corpus: disputed ownership has delayed scientific description of the Kouga mummy.

Researchers say that this discovery is the first of its age in southern Africa.

As well as problems with landowners, the find set off a tussle between local tribes.

Two, the Inqua and the Gonaqua, laid claim to the mummy as a former leader. But provincial government officials - many of them from a third tribe, the Nguni - would not accept their claims.

"The mummy symbolizes our culture for centuries," says Jean Burgess, chief of the Gonaqua, claiming that provincial officials had dragged their feet in allowing its full examination. The officials could not be reached for comment.

Binneman says the disputes are deterring archaeologists from exploring the Kouga Mountains site further. 